\title{
PEMASARAN BIBIT SENGON DI DESA KEDUNGLURAH KECAMATAN POGALAN KABUPATEN TRENGGALEK
}

\author{
Idah Lumahtul Fuad \\ Dosen Fakultas Pertanian Universitas Yudharta Pasuruan \\ Imail: faperta.@yudharta.ac.id
}

\begin{abstract}
ABSTRAKSI
Degradasi hutan serta kebutuhan kayu sebagai bahan baku industri yang terus meningkat sepanjang tahun memungkinkan peluang usaha pembibitan sengon terbuka lebar. Himpitan ekonomi menyebabkan petani cenderung menjual bibit sengon dengan harga murah sehingga efisiensi pemasaran sulit tercapai. Panjangnya saluran pemasaran juga menyebabkan keuntungan yang diterima petani menjadi sedikit. Mengidentifikasi pola pemasaran bibit sengon sehingga diketahui tingkat efisiensinya merupakan tujuan penelitian dan sekaligus menjawab permasalahan yang ditemukan. Penelitian ini dilaksanakan di Desa Kedunglurah Kecamatan Pogalan Kabupaten Trenggalek. Pemilihan tempat dilakukan secara sengaja dengan pertimbangan bahwa masyarakat Desa Kedunglurah telah melaksanakan pemasaran bibit sengon. Sistem pemasaran dianalisis secara deskriptif, efisiensi pemasaran dianalisis dengan nilai margin dan share harga.

Terdapat 6 pola saluran pemasaran dalam usaha pembibitan sengon di Desa Kedunglurah. Saluran terpanjang terdapat pada saluran pemasaran IV yakni petani---makelar---pedagang besar---pengecer---konsumen. Panjangnya saluran pemasaran berarti semakin banyak lembaga pemasaran yang terlibat sehingga keuntungan masing-masing lembaga pemasaran semakin kecil. Keuntungan terbesar yang diterima petani dari pemasaran bibit sengon adalah pada saluran I yakni pada saat petani menjual secara langsung kepada konsumen seharga Rp 1.000,-. Margin pemasaran terbesar terdapat pada saluran pemasaran V dan VI yakni sebesar Rp 750,-. Keuntungan lembaga pemasaran terbesar yaitu Rp 550,dan Rp 500 adalah pada saluran V dan VI dimana petani menjual bibit sengon untuk memenuhi pesanen proyek seharga Rp 250,-. Share harga pada masingmasing saluran pemasaran berturut-turut 100\%, 90\%, 65\%, 65\%, 25\%, $25 \%$. Diketahui bahwa saluran pemasaran V dan VI menunjukkan kondisi pemasaran yang tidak efisien dilihat dari nilai share yang kurang dari $40 \%$. Pola saluran V dan VI tetap dipilih petani dengan pertimbangan kapasitas penjualan yang besar sehingga bisa digunakan untuk memenuhi kebutuhan keluarga ataupun pengembalian modal pinjaman.
\end{abstract}

Kata kunci : bibit sengon, efisiensi, biaya, margin, share harga.

\section{PENDAHULUAN}


Kerusakan hutan (degradasi dan deforestasi) yang sangat parah dengan laju mencapai 1,8 juta hektar per tahun menyebabkan hutan alam sudah tidak mampu lagi menjadi pemasok kayu utama untuk bahan baku industri. Padahal, kebutuhan akan kayu setiap tahun sangat tinggi tak tergantikan. Kebutuhan dunia atas bahan baku kayu pada tahun 2014 diperkirakan setidaknya mencapai 350 juta meter kubik per tahun. Permintaan bahan baku kayu itu diperkirakan cukup tinggi untuk memenuhi kebutuhan pabrik kertas, mebel, pertukangan dan lainnya (Anonymous, 2013). Besarnya peluang usaha budidaya tanaman keras tentunya membuka peluang untuk usaha pembibitan yang dapat dilaksanakan oleh masyarakat secara mandiri.

Di sisi lain, Gerakan Satu Milyar Pohon yang telah diluncurkan oleh Kementerian Kehutanan sebagai langkah pelestarian lingkungan dengan didukung adanya program Kebun Bibit Rakyat (KBR) merupakan peluang tersendiri bagi petani pembibitan sengon. Program ini selain sebagai usaha pelestarian lingkungan diharapkan juga memberikan manfaat ekonomi yakni peningkatan kesejahteraan masyarakat. Pemerintah melalui Kementerian Kehutanan menganggarkan dana sebesar $\mathrm{Rp} \quad 50$ juta/KBR untuk 8.000 KBR tahun 2010, naik menjadi 10.000 KBR pada tahun 2011
(Anonymous, 2012). Program ini dalam jangka panjang diharapkan akan menjadi sarana penyediaan bibit berkualitas, bahkan bisa menjadi sentra pembelajaran bagi masyarakat dalam memperoleh pengetahuan tentang kehutanan.

Aspek penting dalam memperoleh keuntungan berusahatani adalah dengan memerhatikan proses pemasaran yakni kegiatan mengalirkan barang dari petani sampai ke konsumen akhir. Usaha peningkatan produktifitas dengan penerapan berbagai inovasi teknologi akan memunculkan permasalahan baru saat terjadi peningkatan produksi yang terkonsentrasi pada satu sentra produksi yakni resiko harga yang rendah karena penawaran lebih besar dari permintaan. Pada kondisi ini, peranan pemasaran sebagai kegiatan menyalurkan barang dari produsen ke konsumen menjadi sangat penting dalam pembangunan pertanian global.

Menurut Mellor (1969) dalam Anindita (2004), perbaikan pemasaran mendorong peningkatan produksi melalui efek langsung dan tidak langsung. Efek langsung terjadi karena pemasaran menambah harga di tingkat petani melalui turunnya biaya pemasaran dan efek tidak langsung terjadi karena adanya perluasan pasar yang disebabkan konsumen dapat menerima harga lebih rendah yang pada 
akhirnya menaikkan harga di tingkat produsen.

Dalam proses pengaliran barang pertanian dari produsen ke konsumen, terdapat orang atau instansi yang turut membantu proses pengaliran yang disebut sebagai lembaga pemasaran. Lembagalembaga ini menjalankan fungsi-fungsi pemasaran dalam rangka menyediakan barang kepada konsumen tepat waktu dan tepat guna. Lembaga pemasaran mendapatkan balas jasa atas kegiatannya berupa margin pemasaran sehingga harga jual dipasar mengalami perubahan dari harga yang diberikan petani dengan harga yang diterima konsumen. Menurut Soekartawi (2002), kelemahan dalam sistem pertanian di negara berkembang pada umumnya sama, yaitu kurangnya perhatian dalam bidang pemasaran.

Saluran pemasaran yang efisien akan sangat menentukan tingkat produksi dan kualitas bibit sengon yang dihasilkan. Karena dengan adanya saluran pemasaran yang efektif dan efisien akan menghasilkan harga yang sesuai baik pada tingkat petani maupun konsumen, sehingga akan dapat memacu petani untuk lebih giat dalam mengelola usahatani tersebut. Perbedaan harga (margin) pemasaran yang relatif besar merupakan salah satu hambatan pemasaran yang sering dijumpai dalam pemasaran komoditas pertanian.
Dalam komoditas pertanian seringkali dijumpai rantai pemasaran yang panjang sehingga banyak lembaga pemasaran yang terlibat dalam pemasaran tersebut. Hal ini mengakibatkan banyaknya balas jasa atau keuntungan pemasaran yang harus diambil oleh masing-masing lembaga pemasaran, yang akhirnya akan memengaruhi tingkat harga yang diterima petani. Sistem pemasaran yang efisien terjadi bila selisih harga yang dibayarkan oleh konsumen dengan harga yang diterima oleh produsen terdistribusi secara proporsional diantara lembaga pemasaran.

Berdasarkan uraian di atas dapat dirumuskan permasalahan sebagai berikut:

1. Bagaimana pola pemasaran bibit sengon di desa Desa Kedunglurah Kecamatan Pogalan Kabupaten Trenggalek?

2. Bagaimana efisiensi pemasaran bibit sengon di Desa Kedunglurah Kecamatan Pogalan Kabupaten Trenggalek?

\section{TUJUAN PENELITIAN}

1. Menganalisis pola saluran pemasaran bibit sengon di Desa Kedunglurah Kecamatan Pogalan Kabupaten Trenggalek

2. Menganalisis tingkat efisiensi pemasaran menggunakan margin dan share harga 


\section{METODOLOGI PENELITIAN}

\section{Waktu dan Tempat Penelitian}

Penelitian dilaksanakan pada bulan Januari-Mei 2014 di Desa Kedunglurah Kecamatan Pogalan Kabupaten Trenggalek. Pemilihan lokasi dilakukan secara sengaja dengan pertimbangan daerah ini telah melaksanakan pemasaran bibit sengon.

\section{Metode Penelitian}

Metode yang digunakan dalam penelitian ini adalah metode deskriptif yaitu suatu metode dalam meneliti status sekelompok manusia, suatu objek, suatu set kondisi, suatu sistem pemikiran ataupun suatu kelas peristiwa pada masa sekarang. Tujuannya adalah untuk membuat deskripsi, gambaran atau lukisan secara sistematis, faktual dan akurat mengenai fakta-fakta, sifat-sifat serta hubungan antar fenomena yang diselidiki. Responden dalam penelitian ini adalah semua petani yang mengusahakan pembibitan sengon. Penentuan responden untuk lembaga pemasaran dilakukan dengan metode "Snow Ball Sampling" yaitu menelusuri rantai pemasaran bibit sengon dari petani responden sampai ke konsumen akhir.

\section{Analisa Data}

Analisis yang digunakan dalam penelitian ini adalah analisis deskriptif, analisis margin pemasaran dan share harga. Analisis deskriptif digunakan untuk mengetahui pola saluran pemasaran. analisis margin pemasaran dan share harga digunakan untuk mengukur tingkat efisiensi pemasaran.

Margin pemasaran dapat dihitung dengan rumus :

$$
\mathbf{M P}=\mathbf{P r}-\mathbf{P f}
$$

Keterangan :

MP = Margin Pemasaran

$\operatorname{Pr}=$ Harga konsumen akhir

Pf $=$ Harga dari produsen

Besarnya share harga yang diterima petani dengan harga yang diterima konsumen atau lembaga pemasaran dapat dihitung dengan menggunakan rumus :

$$
\mathbf{S p}=\frac{P f}{P r} \cdot 100 \%
$$

Keterangan :

$\mathrm{Sp}=$ Bagian harga yang diterima petani

$\mathrm{Pf}=$ Harga ditingkat petani

$\operatorname{Pr}=$ Harga ditingkat konsumen

\section{HASIL DAN PEMBAHASAN}

\section{Sistem Pemasaran Bibit Sengon}

Bibit sengon sudah dijual pada usia 2 bulan dengan tinggi $5-10 \mathrm{~cm}$ untuk permintaan proyek, sementara untuk pedagang dan konsumen akhir membeli bibit sengon dengan tinggi 20-100cm. Harga bibit sengon berkisar antara $\mathrm{Rp}$ 250,- sampai Rp 1.000,- per batang dan bisa mencapai Rp 5.000,- per batang untuk 
jenis sengon Philiphine. Sebagian besar bibit sengon dijual secara kontan baik pada konsumen langsung maupun kepada lembaga pemasaran. Ada pula petani yang menjual bibit sengon dengan sistem kredit berjangka 1 bulan kepada tengkulak yang telah lama menjalin kerjasama dengan petani.

Terdapat 6 pola saluran pemasaran yang ditemukan pada pemasaran bibit sengon di Desa Kedunglurah yaitu:

$\begin{array}{ll}\text { Saluran I } & \text { : petani ---- konsumen } \\ \text { Saluran II } & \text { : petani ---- tengkulak ---- } \\ & \text { konsumen }\end{array}$

Saluran III : petani ---- pedagang besar --- pengecer ----konsumen

\begin{tabular}{|c|c|c|}
\hline Saluran IV & $\begin{array}{l}\text { petani --- } \\
\text { pedagang }\end{array}$ & $\begin{array}{l}\text { makelar } \\
\text { besar }\end{array}$ \\
\hline
\end{tabular}

Saluran V : petani ---- perusahaan pembibitan --- konsumen (dinas/kelompok tani)

Saluran VI : petani --- petani ---perusahaan pembibitan ---konsumen (dinas/kelompok tani)

Hampir seluruh responden penelitian menjalankan 6 pola pemasaran ini dan hanya sekitar 5 petani responden yang tidak bersedia menjual bibitnya untuk pola ke V dan VI yakni untuk pesanan proyek. Penjualan pada proyek memang lebih cepat mendapatkan keuntungan dengan volume penjualan dalam jumlah besar dan tanpa sortir sehingga untuk petani yang memiliki bibit kurang dari 10.000 batang bisa langsung habis dalam sekali penjualan. Hanya saja harga yang diberikan untuk penjualan proyek hanya sebesar Rp 250,per batang. Petani masih menyetujui harga ini dikarenakan desakan kebutuhan ekonomi serta biaya tenaga kerja keluarga tidak diperhitungkan. Beberapa petani juga menjual sebagian bibitnya untuk proyek dengan harapan pengembalian modal lebih cepat sedangkan sisanya dijual dengan harga yang lebih tinggi yakni berkisar antara Rp 650,- hingga Rp 1.000,- per batang.

Tengkulak dalam sistem pemasaran bibit sengon ini sebagian besar berasal dari Kabupatan Trenggalek sendiri sementara pedagang besar dan konsumen langsung kebanyakan dari luar Kabupaten Trenggalek. Untuk pembelian proyek berasal dari wilayah Blitar, Kediri, Ponorogo, bahkan sampai wilayah Jawa Barat. Proyek ini selain untuk program penghijauan dari Dinas setempat juga dilakukan oleh petani yang mendapatkan proyek Kebun Bibit Rakyat (KBR) dan Kebun Bibit Desa (KBD).

Masing-masing lembaga pemasaran yang terlibat dalam pemasaran menjalankan fungsi pemasaran sehingga mereka mendapatkan balas jasa atas kegiatan mereka berupa margin pemasaran. Adapun fungsi-fungsi pemasaran yang 
Tabel 1 Fungsi-Fungsi Lembaga Pemasaran Bibit Sengon

\begin{tabular}{|c|c|c|c|c|c|c|}
\hline \multirow{3}{*}{$\begin{array}{c}\text { Saluran dan lembaga } \\
\text { pemasaran }\end{array}$} & \multicolumn{6}{|c|}{ Fungsi-fungsi pemasaran } \\
\hline & \multicolumn{2}{|c|}{ Pertukaran } & \multicolumn{2}{|c|}{ Fisik } & \multicolumn{2}{|c|}{ Fasilitas } \\
\hline & Jual & Beli & Simpan & Angkut & Resiko & Sortasi \\
\hline \multicolumn{7}{|l|}{ Saluran I } \\
\hline Petani & $*$ & & $*$ & & $*$ & $*$ \\
\hline Konsumen & & $*$ & & $*$ & & \\
\hline \multicolumn{7}{|l|}{ Saluran II } \\
\hline Petani & $*$ & & $*$ & & $*$ & $*$ \\
\hline Tengkulak & $*$ & $*$ & $*$ & $*$ & $*$ & \\
\hline Konsumen & & $*$ & & $*$ & & \\
\hline \multicolumn{7}{|l|}{ Saluran III } \\
\hline Petani & $*$ & & $*$ & & $*$ & $*$ \\
\hline Pedagang besar & $*$ & $*$ & $*$ & $*$ & $*$ & $*$ \\
\hline Pengecer & $*$ & $*$ & & $*$ & $*$ & \\
\hline Konsumen & & $*$ & & $*$ & & \\
\hline \multicolumn{7}{|l|}{ Saluran IV } \\
\hline Petani & $*$ & & $*$ & & $*$ & $*$ \\
\hline \multicolumn{7}{|l|}{ Makelar } \\
\hline Pedagang besar & $*$ & $*$ & $*$ & $*$ & $*$ & $*$ \\
\hline Pengecer & $*$ & $*$ & & $*$ & $*$ & $*$ \\
\hline Konsumen & & $*$ & & $*$ & & \\
\hline \multicolumn{7}{|l|}{ Saluran V } \\
\hline Petani & $*$ & & $*$ & & $*$ & \\
\hline Perusahaan pembibitan & $*$ & $*$ & $*$ & $*$ & $*$ & \\
\hline Konsumen (Dinas) & & $*$ & & $*$ & $*$ & \\
\hline \multicolumn{7}{|l|}{ Saluran VI } \\
\hline Petani & $*$ & & $*$ & & $*$ & \\
\hline
\end{tabular}


Petani sub

Perusahaan pembibitan

Konsumen (Dinas)

Sumber: Data primer diolah, 2014.

\section{Analisis Efisiensi Pemasaran}

Analisis efisiensi pemasaran diperlukan sebagai pertimbangan petani dalam memilih saluran pemasaran yang menguntungkan. Efisiensi pemasaran menggambarkan pola distribusi keuntungan yang diterima masing-masing lembaga pemasaran dalam usaha mendistribusikan bibit sengon sampai ke konsumen akhir.

Pola saluran pemasaran bibit sengon serta distribusi harga digambarkan pada skema berikut:

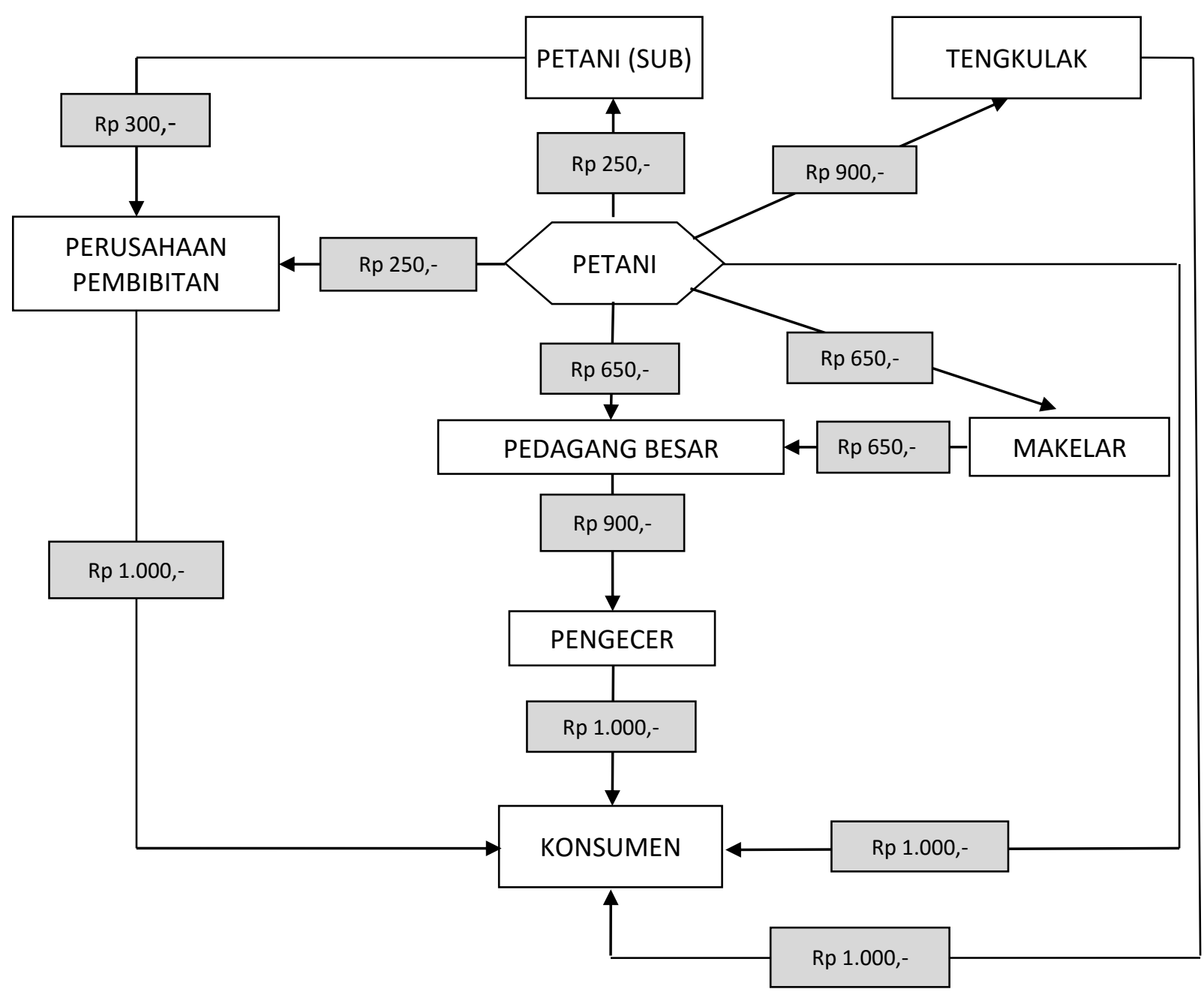

Gambar 1 Pola Saluran Pemasaran dan Distribusi Harga Bibit Sengon di Desa Kedunglurah 
Pada saluran pemasaran I petani menjual bibit sengon langsung kepada konsumen dengan harga $\mathrm{Rp} 1.000$ per batang untuk bibit sengon laut dengan tinggi kurang dari 1 meter. Harga bibit sengon laut yang mencapai 2 meter bisa mencapai Rp 2.000,- per batang sedangkan bibit sengon varietas Philipine harganya Rp 5.000,- per batang. Pada saluran ini seluruh keuntungan yakni sebesar Rp 636,dan Rp 4.629,- untuk bibit sengon varietas Philipine dimiliki oleh petani. Meskipun nilai margin sangat besar tetapi kapasitas pembelian oleh konsumen langsung tidak banyak yakni berkisar antara 10 sampai 200 bibit dalam sekali transaksi.

Pada saluran pemasaran II petani menjual bibit sengon kepada tengkulak dengan harga Rp 900,- per batang. Kapasitas pembelian tengkulak berkisar antara 150 sampai 500 bibit sengon setiap pembelian. Pada saluran ini petani mendapatkan margin yang lebih sedikit dibanding saluran pemasaran I yakni $\mathrm{Rp}$ 536,- per batang. Selanjutnya tengkulak menjual kepada konsumen dengan harga Rp 1.000,- per batang sehingga margin yang didapatkan oleh tengkulak sebesar $\mathrm{Rp}$ 100,- per batang. Nilai margin ini tidak sepenuhnya merupakan keuntungan karena tengkulak harus mengeluarkan biaya pengangkutan dan perawatan serta biaya resiko kerusakan bibit pada saat pengangkutan.
Saluran pemasaran III petani menjual bibit sengon pada pedagang besar dengan harga Rp 650,- per batang untuk kemudian dijual kepada pengecer $\mathrm{Rp}$ 900,- per batang. Pengecer menjual bibit sengon kepada konsumen dengan harga Rp 1.000,per batang. Nilai margin yang didapatkan pada masing-masing lembaga pemasaran pada saluran ini adalah $\mathrm{Rp} 286,-$ untuk petani, Rp 250,- untuk pedagang besar dan Rp 100,- untuk pengecer.

Pada saluran pemasaran IV ditemukan 1 lembaga pemasaran yakni makelar. Makelar dalam hal ini tidak memiliki bibit sengon sendiri tetapi memiliki jaringan kerjasama terhadap pedagang besar untuk mencarikan bibit sengon dalam jumlah dan ukuran yang diinginkan. Makelar tidak membeli bibit sengon dari petani melainkan hanya sebagai perantara sehingga tidak mengeluarkan biaya pengangkutan maupun penanggungan resiko. Makelar mendapatkan komisi sebesar Rp 50,- per bibit dari pedagang besar.

Saluran pemasaran $\mathrm{V}$ dan VI merupakan pemasaran untuk memenuhi permintaan proyek baik dari Dinas maupun dari kelompok tani yang menerima program KBR. Pembelian bibit pada saluran ini biasanya lebih awal yakni pada saat tinggi bibit antara $5-10 \mathrm{~cm}$. Pada saluran pemasaran ini petani menjual bibit sengon dengan harga $\mathrm{Rp} 250,-$ sehingga 
Tabel 2 Margin Pemasaran pada Masing-Masing Saluran Pemasaran Bibit Sengon

\begin{tabular}{lcccccc}
\hline \multirow{2}{*}{ Komponen margin } & \multicolumn{5}{c}{ Saluran pemasaran } \\
\cline { 2 - 7 } & I & II & III & IV & V & VI \\
\hline Biaya pemasaran $(\mathrm{Rp} / \mathrm{btg})$ & - & $\mathbf{5 0}$ & $\mathbf{1 6 5}$ & $\mathbf{2 1 5}$ & $\mathbf{2 0 0}$ & $\mathbf{2 5 0}$ \\
Keuntungan $(\mathrm{Rp} / \mathrm{btg})$ & - & $\mathbf{5 0}$ & $\mathbf{1 8 5}$ & $\mathbf{1 3 5}$ & $\mathbf{5 5 0}$ & $\mathbf{5 0 0}$ \\
Margin $(\mathrm{Rp} / \mathrm{btg})$ & - & $\mathbf{1 0 0}$ & $\mathbf{3 5 0}$ & $\mathbf{3 5 0}$ & $\mathbf{7 5 0}$ & $\mathbf{7 5 0}$ \\
\hline
\end{tabular}

Sumber: Data primer diolah,2014.

Share harga yang diterima petani pada saluran pemasaran I, II, III dan IV berturut-turut adalah sebesar 100\%, 90\%, $65 \%$ dan $65 \%$. Sedangkan pada saluran V dan VI masing-masing sebesar $25 \%$. Menurut Downey dan Erickson (1992) dalam Mukson (2005) bahwa pemasaran hasil pertanian ditinjau dari bagian harga yang diterima petani dapat dikatakan efisien jika nilainya lebih dari $40 \%$. Berdasarkan hasil penelitian menunjukkan bahwa pemasaran bibit sengon pada saluran I, II, III, dan IV dikatakan efisien karena nilainya lebih dari $40 \%$, sedangkan untuk saluran pemasaran V dan VI share yang diterima petani kurang dari $40 \%$ sehingga dikatakan tidak efisien. Meskipun begitu, petani tetap menyetujui permintaan penyediaan bibit untuk kebutuhan proyek meskipun dengan harga yang minim dikarenakan penjualan bisa serentak, tanpa sortir dan dalam jumlah banyak sehingga uang yang diterima dalam jumlah besar sekaligus. Share harga pada masingmasing saluran pemasaran beserta penilaian efisiensinya ditunjukkan pada tabel 3 .

Tabel 3 Share Harga Pada Masing-Masing Saluran Pemasaran

\begin{tabular}{ccccc}
\hline $\begin{array}{c}\text { Saluran } \\
\text { pemasaran }\end{array}$ & $\begin{array}{c}\text { Harga ditingkat } \\
\text { petani (Rp) }\end{array}$ & $\begin{array}{c}\text { Harga ditingkat } \\
\text { konsumen (Rp) }\end{array}$ & Share $(\%)$ & Analisis \\
\hline I & 1.000 & 1.000 & 100 & Efisien \\
II & 900 & 1.000 & 90 & Efisien \\
III & 650 & 1.000 & 65 & Efisien \\
IV & 650 & 1.000 & 65 & Efisien \\
V & 250 & 1.000 & 25 & Tidak efisien \\
VI & 250 & 1.000 & 25 & Tidak efisien \\
\hline
\end{tabular}

Sumber: Data primer diolah,2014. 


\section{KESIMPULAN DAN SARAN}

\section{Kesimpulan}

Terdapat 6 pola saluran pemasaran bibit sengon di Desa Kedunglurah Kecamatan Pogalan Kabupaten Trenggalek:

$\begin{array}{lll}\text { Saluran I } & : \text { petani ---- konsumen } \\ \text { Saluran II } & \text { : petani ---- tengkulak ---- } \\ & \text { konsumen } \\ \text { Saluran III } & \text { : petani ---- pedagang besar -- } \\ & \text {-- pengecer ----konsumen } \\ \text { Saluran IV } & \text { : petani ---- makelar ---- } \\ & \text { pedagang } \quad \text { besar } \\ & \text { pengecer ---- konsumen } \\ \text { Saluran V } & \text { : petani ---- } \\ & \text { pembibitan ---- konsumen } \\ & \text { (dinas/kelompok tani) }\end{array}$

Saluran VI : petani ---- petani ---perusahaan pembibitan ---konsumen (dinas/kelompok tani)

Nilai margin pemasaran tertinggi adalah pada saluran pemasaran $\mathrm{V}$ dan VI yakni sebesar Rp 750,-, sedangkan terendah adalah pada saluran pemasaran II yakni Rp 50,-. Saluran pemasaran I merupakan saluran paling menguntungkan bagi petani karena seluruh keuntungan diterima petani tanpa melibatkan lembaga pemasaran yang lain.

Share harga yang diterima petani pada saluran pemasaran I, II, III dan IV berturut-turut adalah sebesar 100\%, 90\%, $65 \%$ dan $65 \%$. Sedangkan pada saluran V dan VI masing-masing sebesar 25\%. Share harga yang diterima petani pada saluran I sampai IV memang dikatakan efisien karena nilainya lebih dari $40 \%$ sedangkan untuk saluran pemasaran V dan VI share yang diterima petani kurang dari $40 \%$ sehingga dikatakan tidak efisien.

\section{Saran}

Kepedulian Pemerintah melalui penyuluhan mengenai sistem pemasaran yang efisien serta pembentukan wadah (organisasi) yang berfungsi sebagai penyalur bibit sengon dimungkinkan akan membantu mengurangi kerugian petani akibat distribusi margin yang tidak merata serta permainan harga oleh lembaga pemasaran dan penurunan harga di wilayah lain.

\section{DAFTAR PUSTAKA}

Anindita, Ratya (2004). Pemasaran Hasil Pertanian. Surabaya:Papyrus.

Anonymous (2013).2014 Kebutuhan Kayu Dunia Capai 350 Juta Meter Kubik per Tahun (artikel). diakses 13 Nopember 2013 dari http://asiaagro.co.id/berita-dankegiatan/2014-kebutuhan-kayudunia-capai-350-juta-meterkubik-per-tahun/

Departemen Agribisnis Fakultas Ekonomi dan Manajemen IPB (2009).Bunga Rampai Agribisnis Seri Pemasaran.Bogor:IPB Pess 
Kotler, P. (2000). Manajemen Pemasaran

(Analisis,

Perencanaan,

Implementasi, dan Kontrol). Edisi

9. New Jersey:Prentice-Hall.

Rianse,Usman.dkk.(2009).Metodologi

Penelitian Sosial dan

Ekonomi.Bandung.Alfabeta.
Sudiyono, Armand (2001).Pemasaran Pertanian.Malang:UMM Press.

Mukson, S.I.dkk. (2005). Analisis Efisiensi Pemasaran Telur Ayam Ras Di Kabupaten Kendal Jawa Tengah. (jurnal).Fakultas Peternakan Universitas

Diponegoro Semarang. 